Cómo citar este artículo en MLA: Ramírez Valencia, José Raúl. "Del ensimismamiento al acto personalizante”. Escritos 27. 59 (2019): 366-385. doi: http://dx.doi.org/10.18566/escr.v27n59.a09

Fecha de recepción: 11.09 .2019

Fecha de aceptación: 23.10.2019

\title{
Del ensimismamiento al acto personalizante
}

\author{
From Self-Absorption to Personalizing Act \\ Do ensimesmamento ao ato personalizador
}

\author{
José Raúl Ramírez Valencia ${ }^{1}$
}

«Convertíos o como prefiero decir ensimismaos, buscad vuestro verdadero yo, es la que hoy urgirá dar a los hombres» Ortega y Gasset, (VI, 463)

\section{RESUMEN}

El ensimismamiento como categoría antropológica depura la opinión y establece la diferencia entre el hombre y los demás animales. A partir de la obra Ensimismamiento y alteración de Ortega y Gasset, este artículo centra la atención en el ensimismamiento como camino que conduce al sí mismo, a habitar la propia intimidad, a descifrar la auténtica vocación, crear, intervenir y curar las circunstancias, dotándolas de sentido y de significado.

Palabras clave: Ensimismamiento; José Ortega y Gasset; Sí mismo; Alteración.

1 Doctor en filosofía, miembro del Grupo de Investigación Humanitas de la Universidad Católica de Oriente, Colombia. Este artículo hace parte del proyecto de investigación "La autenticidad de la vocación como posibilidad de ser en el pensamiento José Ortega y Gasset”. Proyecto N. 23113. Correo electrónico: jotaraulramirez@gmail.com 


\begin{abstract}
Self-Absorption, as an anthropological category, clarifies opinion and, at the same time, establishes the difference between human beings and the rest of animals. Based on Jose Ortega y Gasset's Ensimismamiento y alteración [Self-Absorption and Alteration], the article focuses on self-absorption as a path towards oneself, to inhabiting intimacy, to finding true vocation, and to creating, intervening and curing circumstances, giving meaning to the latter.
\end{abstract}

Key words: Self-absorption; Jose Ortega y Gasset; Oneself; Alteration.

\title{
RESUMO
}

O ensimesmamento enquanto categoria antropológica limita a opinião; ao mesmo tempo ele estabelece a diferença entre o homem e os demais animais. A partir da obra Ensimesmamento e alteração de Ortega e Gasset, esse artigo foca sua atenção no ensimesmamento como caminho que conduz a si mesmo, a viver a própria intimidade, isto ao decifrar a autêntica vocação, criar, intervir e curar as circunstâncias, no intuito de dar-lhes sentido e significado.

Palavras chaves: ensimesmamento, Ortega y Gasset, si mesmo, alteração.

Palavras chaves: Ensimesmamento; Jose Ortega y Gasset; Si mesmo; Alteração.

\section{Introducción}

$\mathrm{E}$ star alerta o alterados frente a lo que pasa fuera del mundo interior -como las noticias y los hechos sociales-, sin acompañarlos de una adecuada reflexión, es uno de los fenómenos que más desestabiliza a la sociedad. La verdad queda a merced de las circunstancias y de sus interpretaciones o en no pocas ocasiones al arbitrio del consenso de las gentes. Con el auge de las redes sociales y el protagonismo de los medios de comunicación ha aumentado la interacción y la participación de las personas en diferentes temas que atañen a la sociedad, liquidando la mediación del análisis por parte de expertos. Hoy todos quieren opinar, con conocimiento o sin él; lo importante es expresar el parecer con respecto a determinado asunto público o privado. Según Byung-Chul Han, esta realidad obedece a "la desmediatización que pone fin a la época de la representación. Hoy cada uno quiere estar presente él mismo, y presentar la opinión sin ningún intermediario. La representación cede paso a la presencia, o la copresentación" (En el enjambre 34-35). ¿Cómo comprender e intervenir este fenómeno social? La propuesta orteguiana es el ensimismamiento como itinerario hacia sí mismo. 
A mayor alteración menor sentido auténtico de lo social y a mayor ensimismamiento mayor posibilidad de una auténtica sociedad ${ }^{2}$. Ortega hace un comentario agudo con respecto a la sociología, argumentado que Comte, Spencer y Bergson han escrito una cantidad de páginas que hablan de sociología pero no dicen nada en concreto sobre esta ciencia. Sus aproximaciones han sido tangenciales, no han entrado en el meollo de lo social. En el escrito Ensimismamiento y alteración, de una forma distinta, haciendo uso de la fenomenología ${ }^{3}$, Ortega se atreve aproximarse a lo social y a la sociedad, no sin antes advertir que "es un tema, si quiere, bastante humilde, desde luego, poco lucido y, lo que es peor, de sobra difícil [...] Pero el tema es urgente" 4 (V, 1939549). Seguidamente, pone en evidencia la ignorancia y ambigüedad de las gentes con respecto a un conjunto de conceptos que tienen que ver con la sociedad y lo social:

Hablan los hombres hoy, a toda hora, de la ley y del derecho, del Estado, de la nación, y de lo internacional, de la opinión pública y del Poder público, de

2 Ortega desarrolla el tema en diferentes momentos. En el año 1933 en La Nación publicó el artículo: "Sobre ensimismarse y alterarse", enfatiza la relación del hombre con la circunstancia y la importancia del pensamiento para interpretar la misma. (V 251). El 27 de octubre de 1939 en una nota que lleva su firma escribe: "bajo el epígrafe Ensimismamiento y alteración, doy al público la primera lección del curso titulado: "Seis lecciones sobre el hombre y la gente", que estoy desarrollando en la Asociación de Amigos del Arte, de Buenos Aires, y que en su casi totalidad puede desintegrarse del resto de ese curso, como prólogo a él. Algunos puntos que esta lección no hacen sino anunciar, sobre todo el toque de bélico clarín contra ciertas frivolidades de los sociólogos". (V 527). Luego el texto se incorporó a la edición póstuma del curso de $E l$ hombre y la gente que dio en Madrid entre 1949 y 1950 (X 139-323). Hasta ese entonces el escrito era inédito.

3 Sobre la fenomenología de Ortega, Ledesma Pascal, hace referencia al ensimismamiento visto desde la fenomenología 50-53. Y Fernández Zamora afirma: "En Ortega podemos hablar de la elaboración de una fenomenología a la que podríamos llamar existencial, aunque dada la aversión que él mismo tenía por el término quizás podríamos llamarla "fenomenología de la vida" o "perspectivismo" término que popularizó García Morente" (122)

4 Ortega arremete contra la sociología afirmando: "He aquí cómo la ineptitud de la sociología, llenando las cabezas de ideas confusas, ha llegado a convertirse en una de las plagas de nuestro tiempo. La sociología, en efecto, no está a la altura de los tiempos" (V 534) 
la política buena y de la mala, de pacifismo y belicismo, de la patria y de la humanidad, de justicia e injusticia social, de colectivismo y capitalismo, de socialización y de liberalismo, de autoritarismo, de individuo y colectividad, etcétera, etcétera (V 531.)

Creer que el común de la gente comprende estos términos, y aceptar sin ningún filtro que todo individuo exprese su parecer, son los problema más serios que enfrenta la sociedad actual. En concreto, un hacer uso de los usos sociales sin pasarlos por un yo analítico y crítico. Muchas de estas ideas, "confusas y superlativamente vagas" de muchos ciudadanos de a pie están configurando los escenarios de la posverdad ${ }^{5}$. Por ello es muy importante educar y agudizar el criterio para distinguir las opiniones con fundamento de las que son vagas, confusas y falaces, es decir, el problema no se encuentra en el expresar sino en el instituir una opinión como verdad.

En un curso dirigido a los argentinos entre 1939-1940, Ortega y Gasset expresa:

Casi todo el mundo está alterado, y en la alteración el hombre pierde su atributo más esencial: la posibilidad de meditar, de recogerse dentro de sí mismo para ponerse consigo mismo de acuerdo y precisarse qué es lo que cree y qué es lo que no cree; lo que de verdad estima y lo que de verdad detesta (V 534).

La ambigüedad y la crisis que padece la sociedad tiene una causa no fácil de identificar por las ciencias sociales: la alteración y la efímera capacidad de ensimismamiento que reduce al ser humano a una escala animal, donde solo vive desde la tétrica confusión de la dictadura de lo que se dice sin ningún análisis a partir del yo personal.

Ensimismamiento y alteración es el título de una conferencia pronunciada en Buenos Aires, como preámbulo a un curso de seis encuentros sobre $E l$

5 Posverdad es toda información o aseveración que no se basa en hechos objetivos, sino que apela a las emociones, creencias o deseos del público. El prestigioso diccionario inglés de Oxford la distinguió en el 2016 con el título honorífico de palabra del año. También la palabra fue incluida en la actualización del diccionario de la lengua española del 2017. Cf. Huepe Cristian, Peña Tobar Fredy y Pablo Martinez. Dossier 25-35 
hombre y la gente. En realidad, el tema de fondo era "lo social". Suspicazmente, Ortega descalifica los distintos estudios de la sociología al describirlos como meros gritos sin ninguna rigurosidad académica: "Cuando los hombres no tienen nada claro que decir sobre una cosa, en vez de callarse suelen hacer lo contrario: dicen en superlativo, esto es, gritan. $\mathrm{Y}$ el grito es el preámbulo sonoro de la agresión, del combate, de la matanza" (V 534). Ortega se refería indirectamente a la crisis de España, donde las gentes opinaban y hablaban con incipiente conocimiento de la realidad pero con asombrosa altanería.

Por tanto, antes de analizar el fenómeno social hay que reconocer la importancia del ensimismamiento como camino purificador y potenciador de lo social.

\section{El ensimismamiento: atributo esencial del hombre}

A la pregunta ¿quién es el hombre?, Ortega respondería: el hombre es aquel que es capaz de ensimismarse y gracias a esta capacidad se diferencia del animal. Para acuñar esta afirmación, acude al análisis del comportamiento de los simios. Estos viven en perpetuo azoramiento, en contraste con el hombre que tiene la capacidad de recogerse dentro de sí.

El animal es pura alteración. No puede ensimismarse. Por eso, cuando las cosas dejan de amenazarle o acariciarle; cuando le permiten una vacación; en suma, cuando deja de moverle y manejarle lo otro que él, el pobre animal tiene que dejar virtualmente de existir, esto es: se duerme (V 536)

En el artículo de 1937, Bronca en la física, publicado en el diario La Nación de Argentina, Ortega asimila el ensimismamiento con la serenidad, característica esencial de donde brotan todas las notas distintivas de la especie humana:

La serenidad es el atributo primario del hombre. Todos sus demás dones o no son específicamente humanos o son fruto nacido en la gleba noble de su

6 Tres lugares son especialmente importantes en la obra de Ortega para el estudio comparativo entre el hombre y el mono: En torno a Galileo, (VI, 426-427); Ensimismamiento y alteración, (V, 531-550); Ideas y creencias, (V, 677-678). 
serenidad. Cuando el hombre la pierde decimos que está fuera de sí, esclavo de la inquietud de su contorno, en perpetuo azoramiento y nerviosismo (V 418).

Ortega identificó y contrapuso dos situaciones propias del hombre: la alteración, que asedia e identifica a los animales y que el hombre también puede padecer, y el ensimismamiento, atributo propio del ser humano que le posibilita meterse dentro de sí, es decir, reposar y meditar. Mientras que el animal vive prisionero y en constante reacción a lo que ocurre a su alrededor, el hombre tiene la capacidad de entrar dentro de sí.

Ensimismamiento es una palabra que, por su significado y su relación con la antropología, tiene una función relevante en el pensamiento orteguiano. En muy diversos lugares de su obra, la señala como nota propia del hombre frente al animal. Además, en la capacidad de ensimismarse descubre las características que identifican al ser humano, sin las cuales es imposible una analítica propia del ser humano. Aunque aceptando la importancia que Ortega le concede al ensimismamiento, es necesario "corregirlo en cuanto la continuidad entre el animal y el hombre, entre ellos solo se da una diferencia de grado [...] aun siendo una diferencia de grado, se comprende perfectamente la postura de Ortega, quien veía en el ensimismamiento una novedad absoluta" (Alonso Fernández 122).

\section{Ensimismamiento, espléndido vocablo}

¿Qué es ensimismarse? A esta pregunta, esencial por cierto, Ortega responde con profunda claridad:

Solemos llamar a esa operación: pensar, meditar. Pero estas expresiones ocultan lo que hay de más sorprendente en ese hecho: el poder que tiene el hombre de retirarse virtual y provisionalmente del mundo y meterse dentro de sí, o dicho con un espléndido vocablo, que solo existe en nuestro idioma: que el hombre puede ensimismarse (V 537).

La palabra poder en esta definición no es acomodaticia, tampoco es una expresión meramente idiomática; es, más bien, un verbo fundamental e incisivo que implica rompimiento y distancia con el entorno y, a la vez, decisión 
y permanencia en el habitar de la inquieta tranquilidad de uno mismo. Todos los seres humanos tenemos el poder, no delegado, tampoco implorado a las divinidades, de retirarnos del mundo y meternos en nosotros mismos, solo que no todos los humanos hacen uso de tan magistral poder, por eso viven en la tiránica y somnolienta masa social.

Tampoco Ortega considera el poder de distanciarse del mundo y meterse dentro de sí algo dado o inherente al ser humano: "no son dones hechos al hombre. Nada que sea sustantivo ha sido regalado al hombre. Todo tiene que hacérselo a él" (V 537). El hombre para ensimismarse imperativamente tiene que esforzarse, habituarse y poner en acción esta tremenda y maravillosa facultad de meterse en sí mismo. Este fenómeno da pie a Ortega para describir la oposición tensa y aguda entre ensimismamiento y alteración. El animal está volcado hacia el mundo exterior, fuera de sí, hacia lo otro, por consiguiente alterado. El hombre, aunque rodeado por las cosas, se halla en una actitud diferente: puede distanciarse y ponerse de espaldas al mundo, como también puede meterse dentro de sí y atender su propia intimidad. Ahora bien, refugiarse no es sinónimo de meterse; refugiarse implica evasión y miedo, mientras que meterse implica libertad y distancia para enseñorearse de las circunstancias, opiniones y cuidarlas-curarlas a través de la meditación. Quien se refugia solo reacciona, no actúa con decisión en busca del sí mismo. El ensimismamiento es una acción que denota la diferencia entre el hombre y el animal.

\section{La alteración, un atropello existencial}

Expresiones como "atropello", "estafa de nosotros mismos", "escamoteo de nuestro propio ser", "tiranía de lo otro", "dejar de existir", "modorra infrahumana", "ser perdido" o "náufrago en las cosas", significan una existencia que no difiere de la existencia zoológica (Cfr. V 537). Con ellas, Ortega fustiga y describe la alteración que padece el ser humano. Incluso en la lección VI, titulada "Cambio y crisis", del texto En torno a Galileo, hace alusión al tema de la alteración a partir de la atención: "No hay duda que en todo ser animado, el más importante de sus mecanismos es la atención. Estamos allí donde atendemos [...] dime a lo que atiendes y te diré quién eres" (VI 427). Si el ser humano está atento solo al mundo exterior, está alterado, es decir, "obnubilado, ciego, y obligado a actuar mecánicamente en un frenético sonambulismo" (V 534) ¿No será este el diagnóstico social de nuestros tiempos? 
Esta enajenación del ser humano causada por el latrocinio implacable de la alteración y la imponente contaminación de las opiniones sin un sujeto reflexivo y creador, más bien masificado y altanero, Ortega la refirió en el año 1933, cuando la sociedad aun no estaba tan interconectada. El hombre posmoderno vive saturado, alterado, bombardeado de publicidad por doquier. De hecho, el exceso de avisos es considerado contaminación visual, también el ruido estruendoso de las opiniones en los medios de comunicación y el estrepitoso y azorante mundo de las redes sociales que enajenan y unidimensionan al sujeto en lo otro sin el sí mismo, es decir, dejándolo sin una interioridad propia que serene e intervenga el mundo exterior.

En la misma lección, Ortega reflexiona y pone como una de las causantes de la crisis la inestabilidad en que "el hombre se ha quedado sin mundo, entregado de nuevo al caos de la pura circunstancia, en lamentable desorientación" (VI 423). Todo esto proviene de la tiranía y permanente opinión, además de la sustitución del encuentro "cara a cara" por la interacción virtual y fugaz que mantiene al hombre alterado. Las opiniones, en vez de darle mundo y sentido, lo están convirtiendo en un ser que a duras penas deambula entre el espacio y el tiempo, pues el exceso de alteraciones, ruidos exteriores y tareas provenientes de los usos sociales lo están dejando sin estructura íntima para responder acertadamente como ser humano: "Un exceso de sobresalto, una época de muchas alteraciones sumerge al hombre en la naturaleza, lo animaliza, esto es, lo barbariza" (VI 427).

Estas expresiones son un fiel retrato de cómo en la alteración el sujeto permanece desvivido y falseado de su mundo interior. El problema radica también en que la mayoría de las personas no caen en la cuenta de que están viviendo en una pseudo-intimidad que ha configurado el mundo exterior. $\mathrm{Al}$ respecto dice Ortega:

Yo creo que la mayor parte de los hombres vive una vida interior, en cierta manera, apócrifa. Sus opiniones no son, en verdad, sus opiniones, sino estados de convicción que reciben de fuera por contagio, y lo que creen sentir no lo sienten realmente, sino que, más bien, dejan repercutir en su interior emociones ajenas. Solo ciertas individualidades de selecta condición poseen el peculiar talento de distinguir dentro de sí lo auténtico de lo apócrifo y logran eliminar cuanto ha inmigrado en ellos desde el contorno. (II 455-456). 
Byung-Chul Han, pensador surcoreano, aunque no con la misma palabra alteración, ni tampoco con apócrifa intimidad, describe desde otra perspectiva la alteración que vive el sujeto contemporáneo al referirse a diferentes actividades que realiza sin ningún núcleo interno unificador de su vivencia:

\begin{abstract}
Viajamos por todas partes sin tener ninguna experiencia, uno se entera de todo sin adquirir ningún conocimiento. Se ansían vivencias y estímulos con los que, sin embargo, uno se queda siempre igual a sí mismo. Uno acumula amigos y seguidores sin experimentar jamás el encuentro con alguien distinto. Los medios de comunicación representan un grado nulo de lo social (La expulsión de lo distinto 12).
\end{abstract}

Esta cita da razón de un sujeto alterado que quiere acumular experiencias como se acumulan cosas: para él, entre más vivencias mayor distracción, dado su incipiente ensimismamiento. Estas experiencias, más que centrarlo lo convierten en un fugitivo de sí mismo, aunque en apariencia se busca a sí mismo, solo que no ha podido encontrarse porque su apuesta es por la experiencia sin interioridad, sin un paso por el yo meditativo del sujeto.

Desde otra perspectiva, el mismo Byung-Chul Han analiza cómo a nivel social se ha formado un enjambre digital donde los individuos viven aislados sin poder formar un nosotros social, dada la hipercomunicación digital sin ninguna reflexión previa. Esta sociedad sin reflexión se caracteriza por la ausencia del respeto, la mirada sin distancia, la indignación sin diálogo y sin discurso y la comunicación donde todos producen y comunican información sin mediación alguna; por tanto, estamos formando un enjambre que solo produce alteración personal y social (Cf. En el enjambre 13-39).

\title{
La intimidad: lugar seguro para el hombre
}

¿Tendrá sentido identificar la alteración que sufre el ser humano sin presentar una alternativa antropológica? Ortega responde: "El hombre es el animal que ha logrado meterse dentro de sí, cuando el hombre se pone fuera de sí desciende y recae en la animalidad" (V 546). En su antropología invita a "invertir la puntería dirigiéndola hacia sî" (V 427). Pero ¿qué es ese sí? Ese sí, aunque tiene una gran fuerza gramatical, hay que complementarlo con la palabra mismo, no es igual el sí, al sí mismo. El sí, se refiere al sujeto que se retira, pero no se 
adentra, a diferencia del sí mismo que no solo es sujeto, además es un sujeto que hace que el mundo habite su yo a través de la meditación. La misma palabra ensimismamiento da razón del en sí y del sí mismo: en sí, es solo el sujeto, en sí misma, es el sí mismo, habitado y atravesado por la reflexión. El sí mismo es una afirmación existencial y categórica que afirma el núcleo personalizador del sujeto.

En este sentido, Ortega hace una aclaración más: "El ensimismamiento como todo lo humano, es sexuado, quiero decir que hay un ensimismamiento masculino y otro ensimismamiento femenino [...] ya que la mujer no es sí mismo, sino sí misma"7 (V 548), una razón más para enfatizar la importancia del sí mismo y no solo el en sí. No es lo mismo una personalidad femenina a una personalidad masculina, pues cada personalidad expresará las notas características de su sexualidad de acuerdo con el grado de ensimismamiento. Con esta idea se amplía el panorama de la presencia de la mujer en la sociedad, pues si el hombre encuentra la manera de enriquecer las circunstancias siendo sí mismo, la mujer, de la misma manera, será un referente y un ser potenciador de una cultura nueva siendo sí misma, pero solo puede ser sí misma sí reconoce que su ensimismamiento es diferente al del hombre. En diferentes escritos, con gran señorío y talante masculino, Ortega reflexiona sobre el femenino y su aporte la cultura. ${ }^{8}$

En este mismo sentido, Julián Marías, discípulo de Ortega, hace una precisión interesante en cuanto la diferencia del hombre y la mujer. Según él, cada ser humano está instalado en su condición sexuada: varón o mujer, esa es la manera concreta de vivir tanto la mundaneidad como la corporeidad, y, desde esa instalación sexuada, se proyecta en diversas direcciones. Para Marías, toda realidad, incluso las más remotas de la sexualidad como el comer, comprender un teorema matemático, contemplar un paisaje, presenciar un acto religioso o vivenciar un peligro, se vive desde la instalación sexual, en un contexto y desde

7 La cursiva es de Ortega.

8 En el capítulo VI de El hombre y la gente, titulado: Más sobre los otros y yo - Breve excursión hacia ella. Ortega profundiza más detenidamente la diferencia entre el hombre y la mujer. X, 213-233. En otros textos también expone estas diferencias. Epílogo de Francesca A Beatrice, III, 725-742, La poesía de Ana de Noailles, V, 149 155, V, Amor en Stendhal V, 465-495, Meditacioens sobe la criolla, IX, 230- 261. 
una perspectiva, ya sea de varón o mujer y que no cabe la reducción de la una a la otra (cf. Marías 117).

La intimidad no es solo el retiro del hombre del mundo sino el lugar donde el hombre retirado medita, cuida-cura el mundo, sopesa y ahonda su autenticidad. Además, es el lugar donde el hombre y el mundo se encuentran despojados de la artificiosa seguridad de las apariencias y de las opiniones sin reflexión que balbucean las masas en aras de una nueva seguridad nacida del sí mismo. En la interioridad de sí el ser humano se unifica y encuentra la identidad que humaniza las circunstancias, mientras que en la exterioridad el individuo se dispersa y se deshumaniza.

Ortega califica la atención hacia adentro como el hecho más antinatural y ultrabiológico, además de ser el más primitivo que marca la diferencia entre el hombre y el animal (Cfr. V 538) ${ }^{9}$. Es tan antinatural que es a través del dentro que la misma naturaleza del ser humano alcanza su cima, su estado propio y su puesto en medio de las circunstancias. El hombre, por su capacidad de ensimismamiento, descubre que el mundo es inseguro, fluctuante y dominante; por ello necesita afirmar su intimidad frente al mundo como lugar seguro y sereno y desde allí acrisolar las ideas sobre las cosas y salir con su yo renovado con un cierto ímpetu o proyecto personal que hace que el mundo quede impregnado del sí mismo nacido de la meditación.

Como el animal no tiene intimidad y en consecuencia tampoco imaginación, su conducta es regida totalmente por las leyes de la naturaleza, es decir, por las ciencias físicas. El hombre, en cambio, no se agota, ni se reduce, ni se encasilla en la razón física: su existencia incumbe más a la razón vital-histórica, donde a través de su intimidad amalgama y entreteje un mundo plasmado de imaginación que la razón física no alcanza a captar ni capturar. Al respecto, el filósofo español escribe: "El animal tiene que estar fuera de sí [...] Y no tiene intimidad, esto es, mundo interior, porque no tiene imaginación. Lo que llamamos nuestra intimidad no es sino nuestro imaginario mundo, el mundo de nuestras ideas. Ese movimiento merced, al cual desatendemos la realidad

9 Para Ortega, «el auténtico ser de cada hombre no es algo que le constituye, sino una especie de figura imaginaria, de proyecto irreal, de inexistente aspiración que se ve comprometido a realizar [...] no es un factum, sino un faciendum». (X, 5). 
unos momentos para atender a nuestras ideas, es lo específico del hombre y se llama ensimismarse" (V 677-678) ${ }^{10}$.

\section{El peligro de no ser sí mismo}

$\mathrm{Si}$ algún tema es transversal e incluso identifica a la filosofía orteguiana es precisamente el peligro de no ser sí mismo o más propiamente la autenticidad. En diferentes escritos, el filósofo madrileño acude a este concepto. Al referirse a los argentinos, dice: "ocupan la mayor parte de su vida en impedirse a sí mismos vivir con autenticidad" (II 743). De Goethe: “¡Tienes que ser! Le decía la vida [...] Ya estoy siendo, puesto que actúo sin cesar: hago pucheros, hago vasijas; no descanso un minuto. ¡No basta! Proseguía la vida. No es pucheros o vasijas lo que importa. No basta con actuar. Tienes que hacer tu yo, tu individualísimo destino. Vivir con plenitud es ser algo irrevocablemente" (V 138). En el escrito Ideas sobre Pío Baroja, de 1910, afirma: "Baroja es el caso extrañísimo, en la esfera de mi experiencia único, de un hombre constituido casi exclusivamente por ese fondo insobornable y exento por completo del yo convencional que suele envolverlo" (II 225). Y en otro artículo de 1933, publicado en La Nación, se refiere al yo suplantado "como el yo individual, efectivo, y siempre primitivo, es suplantado por el yo que es la gente, por el yo convencional" (V 259). Nótese que en cuanto Goethe y Pio Baroja se explicita que el yo puede ser suplantado por un yo convencional, y en las otras dos citas el yo auténtico queda absorbido por la masa. La única forma de permanecer en su sí mismo o alcanzar a ser sí mismo es a través del ensimismamiento. Al respecto escribe Ortega:

Cada uno de nosotros está siempre en peligro de no ser sí mismo, único e intransferible que es. La mayor parte de los hombres traiciona de continuo a ese sí mismo que está esperando ser [...] Se comprende muy bien que Píndaro resumiese su heroica ética en el conocido imperativo: llega a ser el que eres. (V 540-541)

10 En esta nota Ortega afirma: «Scheler en El puesto del hombre en el cosmos, entrevé esta diferente condición del animal y el hombre, donde el hombre se puede volver sobre su intimidad y reaccionar a partir de ella creando un mundo imaginario, pero Scheler -dice Ortega- no la entiende bien, no sabe su razón» (V, 677). 
Con esta cita, enfatiza claramente las bases y la necesidad de un estudio serio acerca de ese sí mismo como proyecto y programa ineludible de realización del ser humano. Más aun, en Un Goethe Bicentenario aduce como una de las causas de la felicidad es ser sí mismo: "Cuando el hombre logra [...] ser el que tiene que ser, y de este modo coincide con su auténtico sí mismo, el hombre es feliz" (X 5). Por consiguiente, la felicidad está intrínsecamente relacionada con el sí mismo y la infelicidad es una consecuencia directa de la alteración. Es decir, a mayor autenticidad mayor felicidad y a mayor inautenticidad mayor infelicidad.

Esta búsqueda del sí mismo conduce a nuestro pensador ibérico a la realidad de la vocación, tema esquivo y de poca reflexión en la antropología filosófica o como Ortega prefiere llamarle: el conocimiento del hombre (II 569).

\section{Ensimismamiento y vocación: una diada para enriquecer}

Frente a la díada: ensimismamiento y alteración, se presenta como camino salvador, la díada: ensimismamiento y vocación. Mientras que la alteración distrae, desorienta y conduce al sujeto a un estado de animalidad impidiéndole encontrarse con el sí mismo, la vocación como llamada íntima se impone como categoría autenticada por el ensimismamiento que centra al sujeto en el imperativo del "tener que ser el que se es". Por tanto, la auténtica vocación es un fluir sereno, pero atrevido de un ensimismamiento que continuamente acrisola con el meditar el quehacer del sujeto. De esta manera, el accionar de cada persona no es un bracear como náufrago sin puerto, sino un bracear que crea horizonte personal y social.

La alteración conduce al hombre a vivir de unos yoes apócrifos, a diferencia de la vocación que perentoriamente llama y centra al sujeto a vivir desde el yo profundo. Por tanto, la vocación impide la inautenticidad del yo y la fuga del sujeto en los malabares circunstanciales. Al respecto, escribe Ortega refiriéndose a Goethe:

Cuando tratando de contestar a la pregunta misma que antes he hecho, al angustioso ¿quién soy yo?, él se respondía: una entelequia, empleaba tal vez 
el vocablo mejor para designar ese proyecto vital, esa vocación inexorable en que nuestro auténtico yo consiste. Cada cual es el que tiene que llegar a ser, aunque acaso no consiga ser nunca. (V 129)

Una persona alterada difícilmente se preguntará quién es. Cuando me pregunto ¿quién soy? comienzo a poner en tela de juicio el mundo en el cual vivo y a la vez dispongo mi yo hacia el sí mismo que reclama "llegar a ser el que se tiene que ser". Esta expresión pindárica «es imperativa y orientadora a la vez dado que invita a descubrir y a seguir el camino trazado en el interior de cada uno de nosotros [...] Ante la pregunta ¿quién soy en realidad? La respuesta es un proyecto que se hace vocación" (Ramírez Valencia 74).

\section{El ensimismamiento: camino de autenticidad}

Ensimismamiento y autenticidad en el pensamiento de Ortega caminan juntos, al igual que alteración y falsedad se implican. Un hombre auténtico es alguien que ha pasado el mundo de las opiniones, de los otros hombres y el mundo físico por su sí mismo. Al respecto, argumenta:

Lo contrario de ser sí mismo, de la autenticidad, del estar siempre dentro de sí, es el estar fuera de sí, lejos de sí, en lo otro que nuestro auténtico ser. La voz castellana otro viene de la latina alter. Lo contrario de ser sí mismo o ensimismarse es alterarse, atropellarse [...] El hombre alterado y fuera de sí ha perdido su autenticidad y vive una vida falsa. (VI 425)

Ensimismarse es entrar en sí mismo, ser símismo es ser auténtico y ser auténtico es descubrir el verdadero yo, "la intimidad". El sí mismo es el que discierne con celosa serenidad y ordena con majestuosa impetuosidad el mundo exterior; "mantener frente a lo que hay fuera un huertecillo íntimo, cerrado, libre, un yo, una conciencia de lo bueno y lo discreto, de lo bello y lo ordenado y lo justo. En ese lugarcillo interior se perpetúa la divina fermentación espiritual" (I 374), afirmaba Ortega. Y luego de pasar por ese lugarcillo interior, el hombre regresa motivado al mundo exterior con sentimiento de poderío y de creación.

El objeto del "ensimismamiento", es inventar y encontrar un mundo de ideas que ayuden a orientar la vida en medio de la circunstancia. La realidad que surge del ensimismamiento es un mundo de significados dentro del yo, que 
me orientan y me mueven con seguridad. Ese mundo es el horizonte en el cual puedo situar y comprender el auténtico significado de mis propios actos. El mundo interior no es un segundo mundo irreal al lado del real que existe fuera de mí, sino mi interpretación de la realidad pasada por mí sí mismo, es decir, recreada e interiorizada por mí y para mí. A partir de este proceso se concibe el ensimismamiento como fuente y puente de donde brota y se establece la relación de autenticidad entre el sujeto y sus acciones. El mundo, por tanto, en palabras de Ortega:

El mundo es nuestra proyección, no nuestra representación, como pretendía Schopenhauer: Nada hay dentro, nada hay fuera, lo que hay dentro, eso hay afuera, repite a menudo Goethe [...] las cosas son proyecciones de nuestra intimidad. Lo que anda vagando por los fondos de nuestro corazón, eso andará viviendo a la luz del día. (I 204-205)

Ortega es claro y contundente al proponer el cuidado del mundo y de las cosas a partir del ensimismamiento, solo hay cuidado del mundo si hay cuidado de sí. A través del ensimismamiento se construye sociedad dado que se supera la masificación y la manipulación. Ortega, como teórico de la sociedad, parte del individuo que se conoce y se reconoce a partir del ensimismamiento. Al respecto escribe:

De este mundo interior emerge y vuelve al de fuera. Pero vuelve en calidad de protagonista, vuelve con un sí mismo que antes no tenía -con su plan de campaña-, no para dejarse dominar por las cosas, sino para gobernarlas él, para imponerles su voluntad y su designio, para realizar en ese mundo de fuera sus ideas, para modelar el planeta según las preferencias de su intimidad. (V 537)

La anterior cita explica profundamente el tema filosófico de Ortega y Gasset: "Yo soy yo y mis circunstancias, y si no las salvo a ellas no me salvo yo" (I 757), y a la vez plantea concretamente el desafío de la autenticidad de la vocación; si hay ensimismamiento hay encuentro con lo que tenemos que ser, y siendo sí mismos salvamos las circunstancias: no debe permitirse que sean las circunstancias las que absorban el individualísimo yo. De esta manera, Ortega distingue el "mundo interior" (propio del hombre) y un "mundo exterior" (común al hombre y al animal). 
En otro texto de 1940, Ideas y creencias, cuyo segundo capítulo se titula "Los mundos interiores", Ortega expone con claridad la relación entre el mundo vivido y el mundo pensado, con el fin de complementar lo expuesto en Ensimismamiento y alteración. En las creencias estamos, las ideas las tenemos, y para tener una idea hay que acrisolar nuestro íntimo yo a través del ensimismamiento. Esto significa que el mundo será más escenario de lo humano mientras la realidad sea más mirada con el lente óptimo de la interioridad. $\mathrm{Al}$ respecto escribe Ortega:

Lo que llamamos nuestra intimidad no es sino nuestro imaginario mundo, el mundo de nuestras ideas. Ese movimiento merced al cual desatendemos la realidad unos momentos para atender a nuestras ideas, es lo específico del hombre, y se llama 'ensimismarse'. De este ensimismamiento sale luego el hombre para volver a la realidad, pero ahora mirándola, como con un instrumento óptico, desde su mundo interior, desde sus ideas. (V 677-678)

Todas estas citas, al igual que la diferencia en el tiempo, dan razón de la estrecha relación entre ensimismamiento y autenticidad.

\section{De lo social a la sociedad}

Al comienzo del artículo "Ensimismamiento y alteración”, primer capítulo del libro El hombre y la gente ${ }^{11}$, Ortega plantea como tema urgente el análisis de lo social y la sociedad, dos realidades recíprocas que no se pueden confundir; desentrañar sus diferencias y su auto-implicación es un primer camino que denota curiosidad e interés por parte del sujeto. Ortega no se queda ahí, su propuesta va al fondo al abordar el ensimismamiento como un camino que "mete" el uso social dentro del sujeto para que lo descifre, comprenda, purifique y lo devuelva a la sociedad no como un mero uso ajeno al sujeto sino como un uso personalizado. El hombre ensimismado por imperativo ético consigo mismo debe descifrar el uso social

11 En 1934 Ortega prometía un libro con el título: El hombre y la gente, donde iba a exponer los fundamentos de una sociología. (V, 527). Al comienza expone: ¿No les parece a ustedes que sería una de las mejores maneras de no perder el tiempo por completo dedicarnos a aclararnos un poco qué es lo social, qué es la sociedad? (V, 532). 
que lo ha despersonalizado, aun a sabiendas de que ese uso social es un personaje misterioso. En este sentido, Pellicani (1986) afirma:

lo social es un tercer personaje que se interpone en todas las relaciones interindividuales. Está dotado de una naturaleza singular, casi misteriosa. No es un fenómeno natural, ni tampoco es un fenómeno humano en sentido propio [...] Es por lo tanto una acción sui generis que aparece en la convivencia, pero que no es un simple hecho de convivencia, aunque solo fuera porque, -como modelo y esquema abstracto- preexiste y la regula. Nos encontramos, por lo tanto, frente a un auténtico misterio que solo puede ser desvelado adoptando métodos de detective, es decir, formulando hipótesis para descifrar ese especial jeroglífico que es lo social (96).

En el mes de marzo de 1935 Ortega escribió diferentes artículos para el diario La Nación de Argentina, textos donde compara la sociedad alemana, española y francesa. La sociedad alemana le parece inhibida con respecto a la vida personal, "su ideal no es ser persona, sino funcionario"; se ha automatizado, casi maquinizado. El español, en cambio, se siente en su oficio como dentro de un aparato ortopédico; su oficio le pesa, lo toma con humanidad excesiva. Entre el alemán y el español se encuentra el francés, quien conjuga su ser funcionario y su ser personal. (Cfr. V, 339). Estas tres percepciones manifiestan tres tipos de sociedades donde lo social adquiere diferentes matices dentro de la sociedad.

Después de hacer esta comparación, al final de estos artículos, Ortega se atreve hacer la diferencia entre lo social y la sociedad: "Lo social, lo colectivo, es pues, lo humano deshumanizado, cuasi-materializado, naturalizado [...] y la sociedad, la colectividad sería el medio esencial ineludible para que el hombre sea hombre. Pero entiéndase bien: cuanto hay en la sociedad vino de individuos y en ella se desindividualiza para ser posible nuevos individuos". (V 344) La sociedad es, en este sentido, el órgano donde el individuo se desindividualiza y a la vez puede individualizarse.

\section{El acto personalizante: síntesis del ensimismamiento}

Para Ortega, "la vida es siempre personal, circunstancial, intransferible y responsable". Estos cuatro atributos identifican lo propio de la vida humana (Cf. X 173). 
Personal, la vida es siempre la mía, no es copia ni repetición de otra, pues es a mí a quien me pasa vivir; mi vivir no es el del vecino, es mi propio existir. Circunstancial porque cada uno está rodeado de facilidades y dificultades; ningún hombre ha elegido estar ahí pero se ha encontrado sin preguntárselo en ese entorno. Intransferible, pues cada cual quiera o no, tiene que estar eligiendo, haciendo propio su ser, el peso de las decisiones recaen primariamente sobre mí, el otro no puede elegir por mí. Por último, responsable, es decir, mi hacer ha de tener buen sentido para mí, no es un hacer desprovisto de futuro, una acción responsable me instala en el mañana.

En este mismo capítulo III, "Estructura de nuestro mundo", del libro El hombre y la gente, Ortega complementa con otras palabras que dan respuesta a la alteración que padece el hombre a causa de un sinnúmero de opiniones que agobian, suplantan y falsifican el ser y el actuar del hombre, manifestando no propiamente una vida humana sino más bien una in-humana:

Solo es propiamente humano en mí lo que pienso, quiero, siento y ejecuto con mi cuerpo, siendo yo el sujeto creador de ello [...] Solo es humano lo que al hacerlo lo hago porque tiene para mí un sentido, es decir, lo que entiendo. En toda acción humana, hay pues, un sujeto de quien emana y que, por lo mismo, es agente, autor o responsable de ello"12 (X 173-174).

Estos cuatro verbos: pensar, querer, sentir y ejecutar a los que alude Ortega, basados en el sujeto creador que entiende el significado de lo que hace y a la vez responde de lo que hace, puede denominarse, según pensamiento propio, acto personalizante.

El pensar, querer, sentir y ejecutar, expresan una secuencia: quiero lo que pienso, siento lo que quiero y ejecuto lo que siento. Para llegar al sí mismo tengo que asumir esta lógica, luego tomar posesión de sí mismo y habitar mi intimidad para crear, interpretar y tejer las circunstancias dotándolas de sentido y de significado, solo después de este proceso puedo afirmar que esta acción es mía y soy responsable de ella. Con esta secuencia se concluye que no hay

12 La cursiva es de Ortega. El concepto acto personalizante es propio del autor del presente artículo. 
auténtica responsabilidad sin ensimismamiento y no hay acto personalizante sin ensimismación.

Más aun, para explicar más hondamente lo social, en el cual no hay sujeto creador, Ortega analiza el uso social del saludo y afirma:

Una acción humana a la que falta la condición primordial de lo humano: proceder de alguien determinado, de algún sujeto único - yo, tú, él. Y si nos preguntamos quién es el responsable de ese hacer [...] nos sorprendemos respondiendo con cierta inevitable evidencia: el causante, el responsable de ese hacer mío, que es dar la mano del saludo, es pues, todos, nadie, nadie determinado, la gente, la sociedad, la colectividad (IX 316).

Llama la atención que al comenzar el tema sobre ensimismamiento y alteración Ortega haga alusión a estos conceptos: "Estado, nación, ley, libertad, autoridad, colectividad, justicia, etcétera", se refiera a ellos como "nociones vagarosas, necias, y turbias" y que al final de la lección haga nuevamente referencia a estos conceptos y diga: "nosotros por el contrario vamos a retirarnos de todo ese hablar de la gente, a distanciarnos de la plazuela, del club, del comité del salón, descendiendo verticalmente hasta un estrato donde los mitos no llegan y empiezan las evidencias" (V, p.550). Con esta intuición se descubre que estos temas alteran y "animalizan" al hombre, por lo tanto, el hombre necesita tomar distancia de ellos, es decir, adentrarse y escucharse para construir no desde el afuera como punto de partida para distinguir de entre todas las opiniones la mía, sino el adentro, que transforma estos escenarios públicos en actos personalizantes. Si estos temas no pasan por el ensimismamiento, es imposible hablar de un cambio social y seguirán poniendo en frenesí a los mortales, como diría el mismo Ortega.

A manera de conclusión podría pensarse que lo social es aquello que aparece vaga y superficialmente en la sociedad como una simple opinión sin ningún ensimismamiento, a diferencia del acto personalizante que nace del ensimismamiento. Por tal razón, tenemos sociedades endebles y ficticias donde muchos individuos solo tienen expresiones y comportamiento de lo social, pero muy pocas expresiones y comportamientos nacidos del acto personalizante. Una sociedad que solo expresa lo social sin ninguna reflexión personal es una sociedad que balbucea solo conceptos y tapiza valores sin contenido alguno; 
en cambio, una sociedad que enfatiza y propicia el ensimismamiento depura y actualiza las circunstancias sociales.

\section{Referencias}

Alonso Fernández, Marcos. "El concepto de distanciamiento en la antropología filosófica del siglo XX: Ortega, Blumenberg y Jonas". Eikasia. Revista de filosofía. N. 89, (2019): 115-136. Impreso.

Chul Han, Byung. En el enjambre. Barcelona: Herder, 2018. Impreso.

Chul Han, Byung. La expulsión de lo distinto. Barcelona: Herder. 2018. Impreso.

Fernández Zamora, Jesús Antonio. "La crítica de Ortega y Gasset a la fenomenología. Las influencias de Husserl y Natorp en la elaboración de las Meditaciones del Quijote". Revista de estudios Orteguianos. N. 28. (2014): 117-130. Impreso.

Ledesma Pascal, Felipe. Realidad y Ser. Un ensayo de fenomenología hermenéutica a propósito de Ortega. Madrid: Editorial Complutense, 2001. Impreso.

Marías, Julian. Obras de Julián Marías X. Antropología Metafísica. Madrid: Revista de Occidente, 1971. Impreso.

Huepe, Cristian, Fredy Peña y Pablo Martínez. "Dossier Era la posverdad: Evidencia vs. apariencia”. Revista Mensaje. Vol. LXVII N. 668. (2018): 25-35. Impreso.

Pellicani, Luciano. "La teoría orteguiana de la acción social. Revista española de investigaciones sociológicas". N. 35. (1986): 89-112. Impreso.

Ramírez Valencia, José Raúl. La autenticidad de la vocación en la filosofía de Ortega $y$ Gasset. La más alta posibilidad del ser humano. Ríonegro: Fondo Editorial Universidad Católica de Oriente, 2015. Impreso.

Ortega y Gasset, José. Obras Completas 10 vols, Madrid: Fundación José Ortega y Gasset/ Taurus, 2004-2010. Impreso. 